\title{
Lichenoid mucocutaneous syndrome a variant of para neoplastic pemphigus (PNP) following the treatment of follicular non-Hodgkin's lymphoma with fludarabine
}

\author{
Katz J ${ }^{1}$, Bhattacharyya $\mathrm{I}^{1}$ and Moreb JS ${ }^{2}$ \\ ${ }^{1}$ Department of Oral Medicine, University of Florida, Gainesville, Florida \\ ${ }^{2}$ Department of Medicine, University of Florida, Gainesville, Florida
}

\begin{abstract}
Background: Paraneoplastic pemphigus (PNP) is an autoimmune mucocutaneous disease associated with cancer. Since the original description of the condition, various publications have suggested the presence of a heterogeneous spectrum of paraneoplastic mucocutaneous conditions with clinical features of lichenplanus. Several cases of PNP have been reported following treatment with fludarabine. Methods: We present a case of lichenoid syndrome in a follicular B-cell non-Hodgkin lymphoma (NHL) patient after treatment with fludarabine and review 8 additional published cases of fludarabine related PNP. Results: Our case is unique due to the fact that the patient presented with lichenoid features both clinically and microscopically and responded well to rituximab therapy. According to literature, both skin and mucosa (eyes and gastrointestinal tract) are involved and symptoms start about 1-2 weeks after exposure to fludarabine. Various immunosuppressive treatments have been employed including high dose steroids. Many of these patients developed complications related to the immunosuppressive therapy such as cytomegalovirus, candidiasis and pneumocystis carinii infection and died from respiratory failure. On the other hand, long-term remissions have also been described. Conclusion: Our case represents an unusual case of fludarabine related to mucocutaneous lichenoid syndrome, a variant of PNP, and in view of the outcome in previously described cases, rituximab may be considered a preferred and safe first line therapy for such complication.
\end{abstract}

Keywords: lichenoid mucocutaneous; para neoplastic pemphigus; fludarabine; rituximab

\section{Introduction}

Paraneoplastic pemphigus (PNP) is an autoimmune mucocutaneous disease associated with cancer and was first described in 1990 by Anhalt et al. [1]. Studies have revealed that PNP is associated with mostly hematological B-cell malignancies such as CLL and NHL, but also other solid tumor malignancies [2-4]. Since the first description, different forms of presentation of PNP have been recognized [5-7]. Characteristically, it manifests with diffuse erosions and shallow ulcerations of the oral mucosa extending to the vermillion surface of the lips. Isolated oral lesions, as the first sign, are present in $45 \%$ of cases [4]. The oropharynx and nasopharynx, tonsils, anogenital mucosa, and esophagus may also be affected $[4,7]$. Conjunctival lesions, which may be severe and resemble those seen in cicatricial pemphigoid, are present in about two-thirds of the patients [8]. Cutaneous manifestations have been reported in all but one case, in which there was only oral involvement [9]. Cutaneous lesions with polymorphic manifestation have been previously categorized into five variants: pemphiguslike, pemphigoid-like, erythema multiforme-like, graft versus host disease like and lichen planus-like [10]. Five diagnostic criteria for PNP were introduced by Anhalt

*Corresponding author: Katz J, Department of Oral Diagnostic Sciences, University of Florida, College of Dentistry, Gainesville, Florida, Tel.: +352 273 6685; Fax: +352 294 5311; Email: jkatz@dental.ufl.edu

Received 28 January 2013 Revised 27 March 2013 Accepted 6 April 2013 Published 14 April 2013

Citation: Katz J, Bhattacharyya I, Moreb JS (2013) Lichenoid mucocutaneous syndrome a variant of para neoplastic pemphigus (PNP) following the treatment of follicular non-Hodgkin's lymphoma with fludarabine. J Cancer Res Ther 1: 123-127. doi:10.14312/20524994.2013-19

Copyright: () 2013 Katz J, et al. This is an open-access article distributed under the terms of the Creative Commons Attribution License, which permits unrestricted use, distribution and reproduction in any medium, provided the original author and source are credited. 
et al. [1] and later revised by Camisa and Helm [11] to include major and minor diagnostic criteria. Three of the criteria are laboratory based tests: intraepidermal and /or basement membrane zone deposition of IgG and C3 demonstrated by direct immunofluorescence (IF), serum autoantibodies to multiple types of murine epithelium demonstrated by indirect IF, and serum immunoprecipitation of protein complexes that include $250,230,210,190$, and $170 \mathrm{kDa}$ antigens. However, few cases were reported to have negative IF studies [12]. Those cases meet the clinical criteria for PNP but lack the laboratory criteria and were considered to be either mediated by T-cells or their antibody production was altered by immunosuppression and rituximab they received as a treatment for the underlying malignancy [12].

Since the first report by Bazarbachi et al. [13], several other reports have documented PNP in patients treated with fludarabine [14-18]. Mucocutaneous lesions usually erupt soon after initiation of therapy with fludarabine, either at initial or repeated exposure. The pathogenesis is thought to be related to fludarabine- induced defect in immunosurveilance as the cause of the phenomenon.

The purpose of the present report is to describe an occurrence of mucocutaneous lichenoid syndrome in a follicular B-cell NHL patient after treatment with fludarabine and a response to rituximab therapy. We have also performed a systematic review of the pertinent literature for similar publications.

\section{Case report}

A 56 year old male who was diagnosed with stage IV follicular small cleaved B-cell NHL about 4 years ago and was initially treated with CHOP chemotherapy in combination with rituximab and achieved first remission. His disease relapsed within a year with retroperitoneal lymphadenopathy and was treated this time with cyclophosphamide and fludarabine. After 2 cycles of therapy, he developed diffuse erythroderma and painful oral stomatitis. Skin biopsies showed no evidence of lymphoma involvement. He was treated with topical and oral steroids with improvement but persistent skin rash and oral ulcers. Because of these symptoms, his lymphoma treatment was stopped after 2 cycles of cyclophosphamide and fludarabine. However 7 months later his NHL was in relapse again. He was started on weekly intravenous rituximab $375 \mathrm{mg} / \mathrm{m}^{2}$ as a single agent treatment for his NHL. Patient had excellent improvement in his skin rash and NHL. His erythroderma and skin ulcers worsened again after stopping rituximab and therefore he was restarted on rituximab maintenance given every other week. The patient's skin rash almost completely disappeared but only with partial improvement in his oral ulcers. At this time he was referred to our clinic for consultation in regards to his stomatitis.
Oral exam was significant for severe ulcerations and sloughing of the oral mucosa, whitish hyperkeratotic plaques, desquamative gingivitis with plaque accumulation, and multiple gingival recessions (Figure 1). The tongue was ulcerated and covered by white plaques and by large bulous lesion at the center (Figure 1B). A biopsy from the buccal mucosa revealed superficial stratified squamous epithelium overlying inflamed fibrous connective tissue. A surface layer of keratin, variable thickening of the spinous cell layer along with acantholysis of the membrane zone was noted. . Focal zones of subepithelial separation were observed. The superficial lamina propria contained a dense band-like infiltrate composed of mainly lymphocytes (Figure 2A). Additional frozen sections were submitted to immunofluorescent antibody staining. Staining was positive in a linear pattern along the basement membrane for fibrinogen and negative for IgG, IgM, IgA and C3 (Figure 2B). A diagnosis of chronic lichenoid mucositis with epithelial separation and direct immunofluorescence confirming lichen planus was rendered. Indirect immunofluorescence study was negative for pemphigus vulgaris. The patient responded favorably to treatment with dexamethasone elixir and clobetasol propionate $0.05 \%$ ointment. In view of the microscopic and clinical findings, our final diagnosis was mucocutaneous lichenoid syndrome associated with fludarabine use which responded well to rituximab therapy. Patient died after about 2 years from progressive lymphoma.
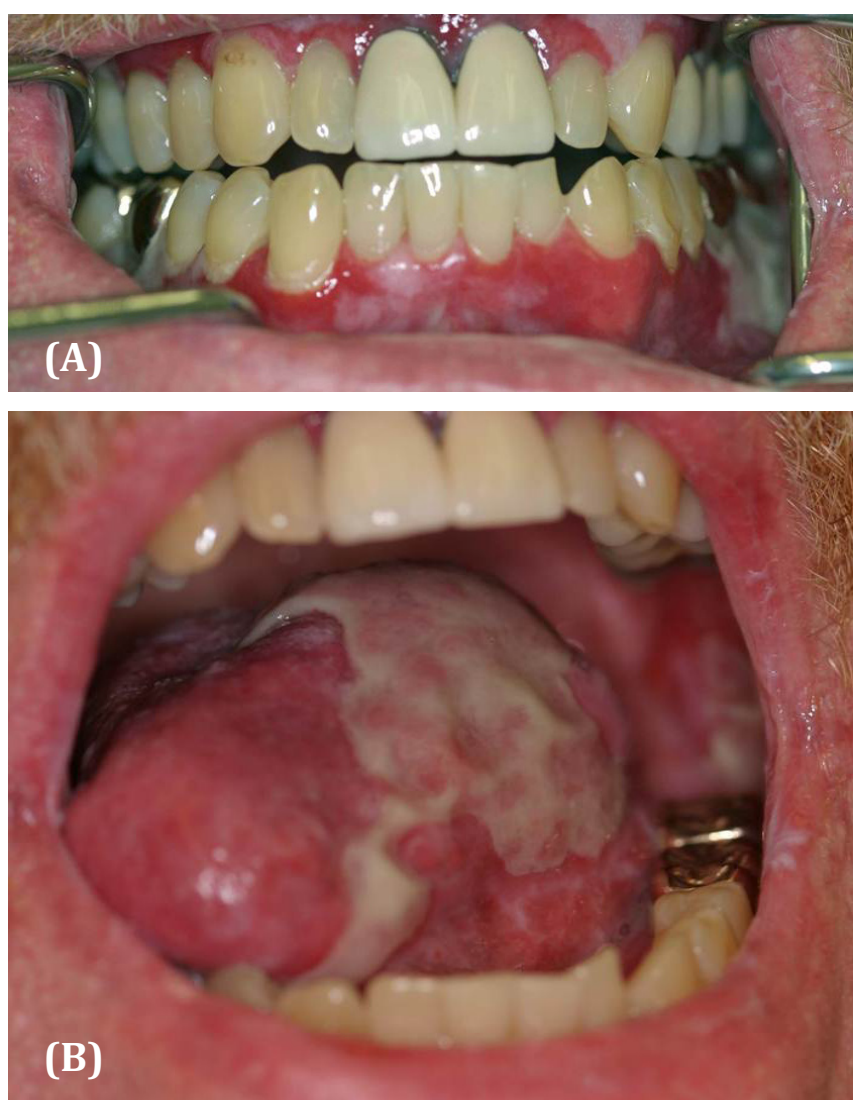

Figure 1 (A) Severe ulcerations and sloughing of the oral mucosa, desquamative gingivitis with plaque accumulation and leukoplakia. (B) Ulcerated tongue covered by white plaques with large bulous lesion at the center 

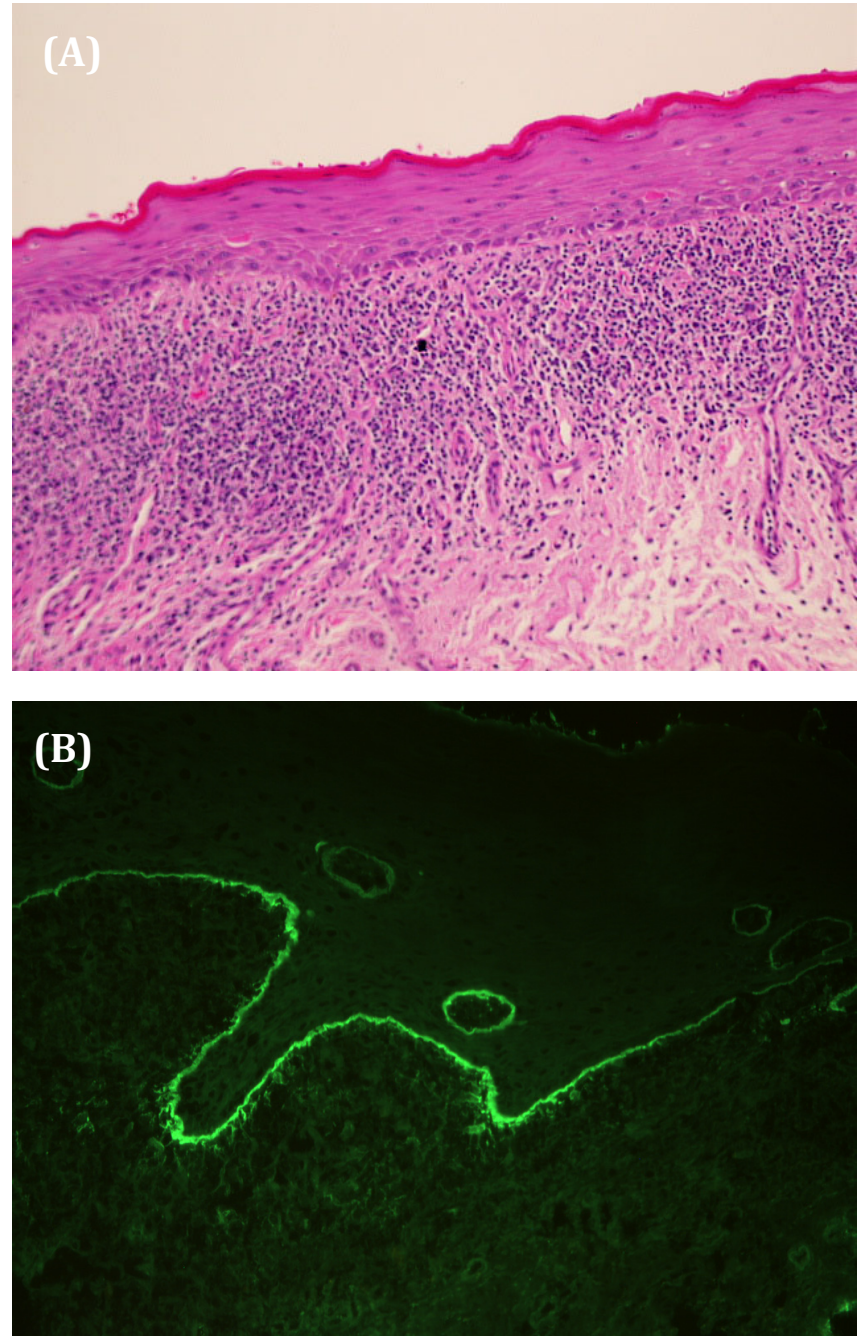

Figure 2 (A) Photomicrograph representing lichenoid mucositis with epithelium exhibiting a thickened layer of parakeratin and minimal thickening of the spinous layer. Occasional eosinophilic degenerative keratinocytes (Civatte bodies) are also seen. Degeneration of the basement membrane zone is evident. A dense band-like lymphocytic infiltrate is noted at the epithelium-connective tissue interface. (Hematoxyllin and eosin stain $\mathrm{x}$ 10). (B) Photomicrograph from direct immunofluorescence antibody staining demonstrating strong positivity for fibrinogen (magnification x 20)

\section{Discussion}

We used PubMed to search for manuscripts describing PNP associated with fludarabine treatment. Only articles published between the years 1970- 2012 were included. The following key words were used: paraneoplastic pemphigus, lichen planus, lichenoid lesions, fludarabine, and rituximab. We have also obtained references from the bibliography of pertinent publications.

After reviewing the literature we identified 8 documented cases of fludarabine associated with the PNP like syndrome. We summarized the findings of patient characteristics and treatment outcomes (Table 1) and the clinical and pathological findings (Table 2). Most occurrences occur in either CLL or low grade NHL, where fludarabine is part of the standard first or second lines of treatment. The age and the male gender predominance most likely reflect the background oncologic diseases. Typically both skin and mucosa (eyes and gastrointestinal tract) are involved and symptoms start about 1-2 weeks after exposure to fludarabine. Some of these cases had other autoimmune phenomena such as autoimmune neutropenia and pancytopenia [14, 17]. Various immunosuppressive treatments are usually used including high dose steroids, cyclosporine (CsA), cyclophosphamide, mycophenolatemofetil (CellCept), azathioprine, plasmapheresis and high dose intravenous immunoglobulins. Our case is unique because of the fact that the patient responded to rituximab treatment which was also beneficial to his NHL. Many of these patients developed complications related to the immunosuppressive therapy such as CMV, candida and pneumocystis carinii (PCP) and died from respiratory failure ( 4 of 9 patients). On the other hand, long-term remissions have also been described ( 5 of 9 patients).

In the present case report we describe a patient with NHL who developed lichenoid mucocutaneous eruptions following treatment with fludarabine. Unlike other reports of fludarabine associated PNP, the histology of the mucosal lesions in our case did not reflect features of pemphigus on the H\&E or direct IF, but were more compatible with a lichenoid reaction.

Theoretically few potential explanatory hypothesis are feasible: (1) This is a manifestation of PNP with the B cell component knocked out by rituximab; (2) A lichenoid syndrome which may be considered within the spectrum of PNP; (3) A lichenoid drug reaction in response to fludarabine ; (4) paraneoplastic phenomenon unrelated to the chemotherapy.

The initial report by Anhalt did not detect an association between the type of chemotherapy and the cases who developed PNP [1]. Interestingly, in one report 5 out of 6 patients diagnosed as having paraneoplastic pemphigus had also features oflichen planus, and therefore the authors concluded that lichenoid eruptions may predispose PNP [6]. Others have reported cases of PNP with predominant lichen planus lesions however with histology consistent with PNP [5]. In a recent study, 4 patients with clinical features of lichenoid variant of PNP with no detectable autoantibodies were described [12]. Three of them received rituximab therapy and the authors speculated that the rituximab may have altered the disease course by preventing development of the antibody-mediated component, leaving the $\mathrm{T}$ cell mediated portion of the disease to proceed. This hypothesis excludes the presence of pemphigus antibody and direct IF features from the diagnostic criteria of PNP.

As shown in Table 1, high-dose steroids was the main treatment modalities in the other reported fludarabine related cases with about $45 \%$ achieving remission for $\geq 6$ months. However, high rate of complications and mortality was also noticed including opportunistic infections and respiratory failure as the leading causes for death. Historically, mortality from PNP has been reported 
Table 1 Patient characteristics and treatment outcomes

\begin{tabular}{|c|c|c|c|c|c|c|}
\hline Reference first author & Age (years) & Gender $M / F$ & $\begin{array}{l}\text { Disease/stage } \\
\text { duration }\end{array}$ & Time from Fludara & Treatment & Outcome \\
\hline \multirow[t]{3}{*}{ Gooptu } & 63 & M & $\begin{array}{l}\text { CLL/stage B } \\
2 \text { years }\end{array}$ & $\begin{array}{l}\text { One week post 3rd } \\
\text { cycle }\end{array}$ & Solumedrol & $\begin{array}{l}\text { Improved, death } 18 \\
\text { months later due to } \\
\text { respiratory failure }\end{array}$ \\
\hline & 58 & M & $\begin{array}{l}\text { CLL/stage B } \\
6 \text { years }\end{array}$ & $\begin{array}{l}\text { Few days post } 3 \mathrm{rd} \\
\text { cycle during } 2 \mathrm{nd} \\
\text { regimen }\end{array}$ & $\begin{array}{l}\text { CTX, solumedrol, } \\
\text { plasmapheresis }\end{array}$ & $\begin{array}{l}\text { Improved, died } 2 \\
\text { months later with } \\
\text { Candida septicemia }\end{array}$ \\
\hline & 54 & M & CLL, 3 years & $\begin{array}{l}\text { Few days after single } \\
\text { course }\end{array}$ & $\begin{array}{l}\text { High dose } \\
\text { solumedrol and } \\
\text { CsA }\end{array}$ & $\begin{array}{l}\text { Remission for } 3 \text { years } \\
\text { on CsA maintenance }\end{array}$ \\
\hline Powell & 69 & M & CLL, 2 years & 2 wks after 2 nd cycle & $\begin{array}{l}\text { Steroids and CTX, } \\
\text { then tapering } \\
\text { steroids with } \\
\text { CellCept added }\end{array}$ & $\begin{array}{l}2 \text { years remission with } \\
\text { scarring of tongue and } \\
\text { pemphigus vegetans. }\end{array}$ \\
\hline Braess & 40 & $\mathrm{~F}$ & Low grade B-cell NHL & One cycle & $\begin{array}{l}\text { High dose } \\
\text { steroids, oral } \\
\text { CTX. IVIg }\end{array}$ & Remission for 6 months \\
\hline Yildiz & 51 & M & $\begin{array}{l}\text { Small cell NHL } \\
16 \text { months }\end{array}$ & 10 day after 6 th cycle & Steroids & $\begin{array}{l}\text { Respiratory failure } \\
\text { with CMV infection on } \\
\text { day } 22 \text {. }\end{array}$ \\
\hline Schierl & 60 & M & CLL, newly diagnosed & 2 wks after FCR & $\begin{array}{l}\text { High dose } \\
\text { steroids, then } \\
\text { maintenance } \\
\text { with added CsA }\end{array}$ & $\begin{array}{l}\text { Died from respiratory } \\
\text { failure two months } \\
\text { later with PCP and CMV } \\
\text { infections }\end{array}$ \\
\hline Our case & 56 & M & $\begin{array}{l}\text { Follicular low grade } \\
\text { NHL, } 4 \text { years. }\end{array}$ & After 2 cycles FC & $\begin{array}{l}\text { Rituxan with } \\
\text { continued } \\
\text { maintenance }\end{array}$ & $\begin{array}{l}\text { Complete skin } \\
\text { response but partial } \\
\text { mucosal response }\end{array}$ \\
\hline
\end{tabular}

Abbreviations: CTX = cyclophosphamide; CsA = cyclosporine; $\mathrm{PCP}=$ pneumocystis carinii; CMV = cytomegalovirus; FCR = fludarabine, cyclophosphamide, rituxan; FC = fludarabine, cyclophosphamide

Table 2 Clinical presentation of fludarabine associated PNP

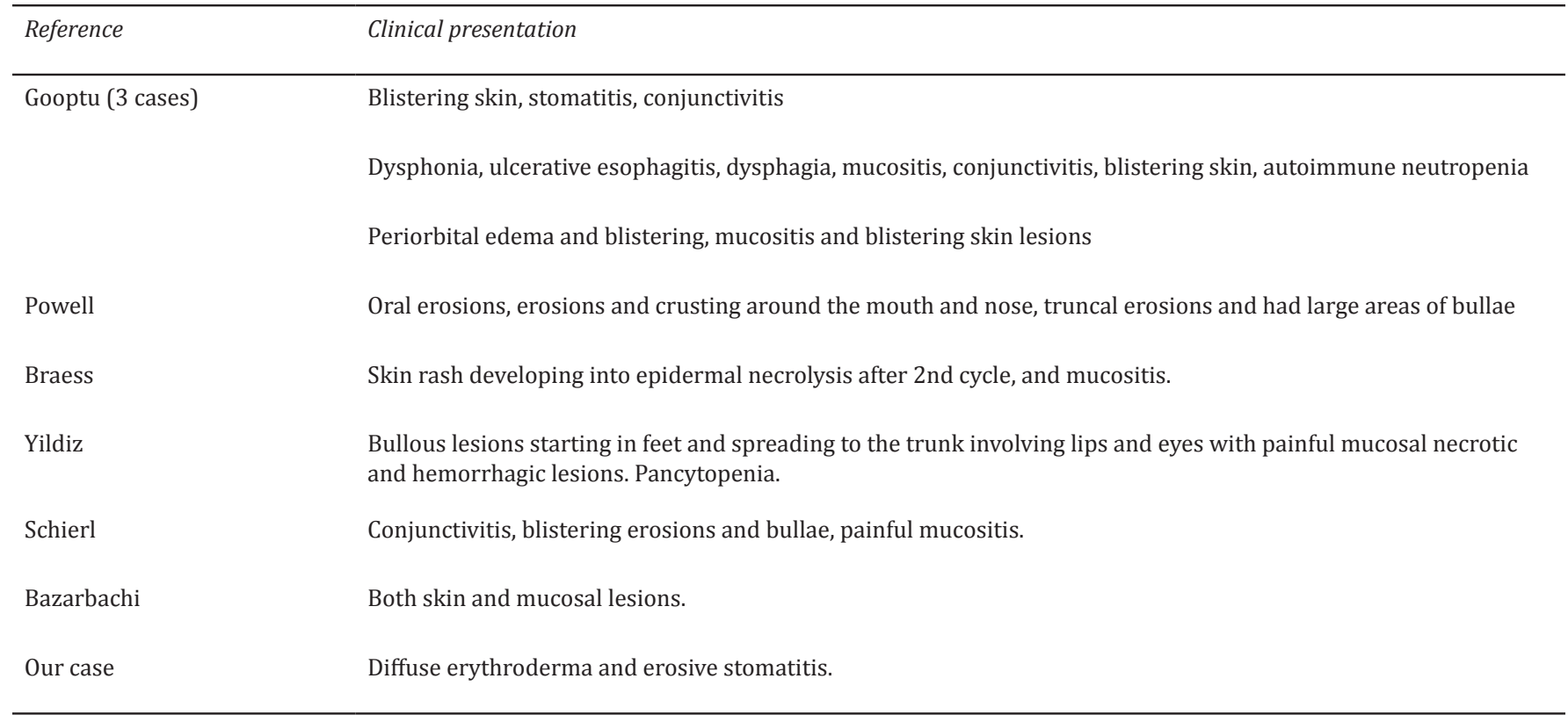

Note: All the above cases, except ours, had laboratory findings in support of the diagnosis of PNP 
to be as high as $90 \%$ [10], and manifestations can include myasthenia gravis and bronchiolitis obliterans $[19,20]$. There are no randomized control trials to guide evidencebased approach to the treatment of PNP, thus multiple treatments have been reported as case reports or in small case series of patients. The response has been variable depending on the underlying malignancy, progression of the disease at the time of treatment, and preexisting comorbidities [21].

In our case, fludarabine therapy preceded the mucocutaneous manifestation and rituximab was administrated subsequently and resulted in the resolution of the skin lesions and partial improvement of the oral lesions, requiring continuous maintenance therapy with rituximab. The advantage of using rituximab in our case is the better tolerability and its activity against the background disease as well. Rituximab has been successfully used to treat PNP $[22,23]$, however rituximabresistant PNP cases have also been reported [24]. Anhalt suggests hematological malignancies induce autoimmune responses against epidermal proteins and these patients present with PNP and not evoked by drugs [25].

\section{Conclusion}

In conclusion, our case represents a fludarabine related mucocutenous lichenoid syndrome, a variant of PNP, and rituximab may be considered a preferred safe first line therapy for such complication.

\section{Conflict of interest}

All the authors declare that they have no conflict of interest.

\section{References}

[1] Anhalt GJ, Kim SC, Stanley JR, Korman NJ, Jabs DA, et al. (1990) Paraneoplastic pemphigus. An autoimmune mucocutaneous disease associated with neoplasia. N Engl J Med 323:1729-1735.

[2] Zhu X, Zhang B (2007) Paraneoplastic pemphigus. J Dermatol 34:503-511.

[3] Steele HA, George BJ (2011) Mucocutaneous paraneoplastic syndromes associated with hematologic malignancies. Oncology (Williston Park) 25:1076-1083.

[4] Kaplan I, Hodak E, Ackerman L, Mimouni D, Anhalt GJ, et al. (2004) Neoplasms associated with paraneoplastic pemphigus: a review with emphasis on non-hematologic malignancy and oral mucosal manifestations. Oral Oncol 40:553-562.

[5] Coelho S, Reis JP, Tellechea O, Figueiredo A, Black M (2005) Paraneoplastic pemphigus with clinical features of lichen planus associated with low-grade B cell lymphoma. Int J Dermatol 44:366371.

[6] Bowen GM, Peters NT, Fivenson DP, Su LD, Nousari HC, et al. (2000) Lichenoid dermatitis in paraneoplastic pemphigus: a pathogenic trigger of epitope spreading? Arch Dermatol 136:652-656.

[7] Taintor AR, Leiferman KM, Hashimoto T, Ishii N, Zone JJ, et al. (2007) A novel case of IgA paraneoplastic pemphigus associated with chronic lymphocytic leukemia. J Am Acad Dermatol 56:S73-76.

[8] Kimyai-Asadi A, Jih MH (2001) Paraneoplastic pemphigus.Int J Dermatol 40:367-372.
[9] Bialy-Golan A, Brenner S, Anhalt GJ (1996) Paraneoplastic pemphigus: oral involvement as the sole manifestation. Acta Derm Venereol 76:253-254.

[10] Nguyen VT, Ndoye A, Bassler KD, Shultz LD, Shields MC, et al.(2001) Classification, clinical manifestations, and immunopathological mechanisms of the epithelial variant of paraneoplastic autoimmune multiorgan syndrome: a reappraisal of paraneoplastic pemphigus. Arch Dermatol 137:193-206.

[11] Camisa C, Helm TN (1993) Paraneoplastic pemphigus is a distinct neoplasia-induced autoimmune disease. Arch Dermatol 129:883886.

[12] Cummins DL, Mimouni D, Tzu J, Owens N, Anhalt GJ, et al. (2007) Lichenoid paraneoplastic pemphigus in the absence of detectable antibodies. J Am Acad Dermatol 56:153-159.

[13] Bazarbachi A, Bachelez H, Dehen L, Delmer A, Zittoun R, et al. (1995) Lethal paraneoplastic pemphigus following treatment of chronic lymphocytic leukaemia with fludarabine. Ann Oncol 6:730-731.

[14] Gooptu C, Littlewood TJ, Frith P, Lyon CC, Carmichael AJ, et al. (2001

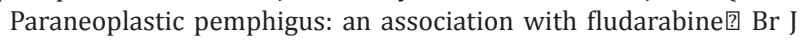
Dermatol 144:1255-1261.

[15] Powell AM, Albert S, Oyama N, Sakuma-Oyama Y, Bhogal B, et al. (2004) Paraneoplastic pemphigus secondary to fludarabine evolving into unusual oral pemphigus vegetans. J Eur Acad Dermatol Venereol 18:360-364.

[16] Braess J, Reich K, Willert S, Strutz F, Neumann C, et al. (1997) Mucocutaneous autoimmune syndrome following fludarabine therapy for low-grade non-Hodgkin's lymphoma of B-cell type (B-NHL). Ann Hematol 75:227-230.

[17] Yildiz O, Ozguroglu M, Yanmaz MT, Turna H, Kursunoglu SG, et al. (2007) Paraneoplastic pemphigus associated with fludarabine use. Med Oncol 24:115-118.

[18] Schierl M, Foedinger D, Geissler K, Rappersberger K, Feldmann $R$ (2008) Paraneoplastic pemphigus despite treatment with rituximab, fludarabine and cyclophosphamide in chronic lymphocytic leukemia. Eur J Dermatol 18:717-718.

[19] Chorzelski T, Hashimoto T, Maciejewska B, Amagai M, Anhalt GJ, et al. (1999) Paraneoplastic pemphigus associated with Castleman tumor, myasthenia gravis and bronchiolitis obliterans . J Am Acad Dermato 41:393-400.

[20] Frew JW, Murrell DF (2011) Paraneoplastic pemphigus (paraneoplastic autoimmune multiorgan syndrome): clinical presentations and pathogenesis. Dermatol Clin 29:419-425.

[21] Frew JW, Murrell DF (2011) Current management strategies in paraneoplastic pemphigus (paraneoplastic autoimmune multiorgan syndrome). Dermatol Clin 29:607-612.

[22] Heizmann M, Itin P, Wernli M, Borradori L, Bargetzi MJ (2001) Successful treatment of paraneoplastic pemphigus in follicular NHL with rituximab: report of a case and review of treatment for paraneoplastic pemphigus in NHL and CLL. Am J Hematol 66:142144.

[23] Anan T, Shimizu F, Hatano Y, Okamoto O, Katagiri K, et al. (2011) Paraneoplastic pemphigus associated with corneal perforation and cutaneous alternariosis: a case report and review of cases treated with rituximab. J Dermatol 38:1084-1089.

[24] Hoque SR, Black MM, Cliff S (2007) Paraneoplastic pemphigus associated with CD20-positive follicular non-Hodgkin's lymphoma treated with rituximab: a third case resistant to rituximab therapy. Clin Exp Dermatol 32:172-175.

[25] Anhalt GJ (2001) Paraneoplastic pemphigus: the role of tumours and drugs. Br J Dermatol 144: 1101-1104. 